\title{
A study of prevalence and association of fundus changes in pregnancy induced hypertension
}

\author{
Varija T. ${ }^{1}$, Vanaja D. ${ }^{1}$, Sindhura $^{2}$, Bellara Raghavenda ${ }^{3} *$
}

\begin{abstract}
${ }^{1}$ Department of Obstetrics and Gynaecology, Vijayanagara Institute of Medical Sciences, Ballari, Karanataka, India ${ }^{2}$ Gynaecologist, Private practitioner, Vijayawada, Andhra Pradesh,India

${ }^{3}$ Department of Community Medicine, Vijayanagara Institute of Medical Sciences, Ballari, Karanataka, India
\end{abstract}

Received: 13 April 2016

Accepted: 22 April 2016

\section{*Correspondence:}

Dr. Bellara Raghavendra,

E-mail: bellararaghu@gmail.com

Copyright: (C) the author(s), publisher and licensee Medip Academy. This is an open-access article distributed under the terms of the Creative Commons Attribution Non-Commercial License, which permits unrestricted non-commercial use, distribution, and reproduction in any medium, provided the original work is properly cited.

\begin{abstract}
Background: The pathological changes of pregnancy induced hypertension appear to be related to vascular endothelial dysfunction and its consequences. The retinal vascular changes generally, but not always, correlate with the severity of systemic hypertension. To find out the prevalence and association of retinal changes in pregnancy induced hypertension.

Methods: A hospital based cross-sectional study was conducted where all antenatal pregnant women who fulfilled the diagnostic criteria of PIH were included in this study. Patients who had pre-existing diabetes or hypertension or renal disease or hazy media which did not permit fundus visualization were excluded from the study.

Socio-demogrpahic and obstetric data was collected and all the patients were subjected to detailed clinical examination followed by fundoscopic examination.

Results: Out of the total 423 patients of PIH examined, the retinal changes (hypertensive retinopathy changes) were noted in $181(42.7 \%)$ patients. The prevalence of retinopathy changes was more among patients with imminent Eclampsia (76.5\%) and eclampsia patients (50\%). As the severity of the PIH increased the Odds of women developing retinopathy also increased substantially from OR: 17.6; 95\% CI: 3.1-136.3 in severe PIH to OR: 253 ; $95 \%$ CI: 47.2-1935 in Imminent eclampsia and this association between the severity of PIH and the development of retinopathy changes was found to be statistically significant.

Conclusions: Fundus examination in cases of PIH is of paramount importance in monitoring and managing cases as it co-relates with the severity of PIH.
\end{abstract}

Keywords: Pregnancy induced hypertension, Retinal changes, Fundoscopy

\section{INTRODUCTION}

Hypertensive disorders complicating pregnancy are one of the common and significant causes of maternal morbidity and mortality especially in developing countries. They are responsible for $8-9 \%$ of maternal deaths in India and $15-20 \%$ of maternal deaths in western world. Overall they complicate $5-10 \%$ of pregnancies in India. $^{1}$
Pregnancy induced hypertension (PIH) is a hypertensive disorder in pregnancy that occurs in the absence of other causes of elevated blood pressure $(140 / 90 \mathrm{mmHg}$, or a rise of $30 \mathrm{mmHg}$ of systolic pressure, or a rise of $15 \mathrm{mmHg}$ of diastolic pressure), taken on two occasions after rest, in combination with generalized edema and/or proteinuria. When there is significant proteinuria it is termed as preeclampsia; seizures or coma as a consequence of PIH is termed as eclampsia. ${ }^{2}$ The incidence of pr-eclampsia in nulliparous population ranges from 3 to 10 per cent worldwide. ${ }^{3}$ Incidence of 
eclampsia in the developed countries is about 1 in 2000 deliveries 4 as compared to developing countries, ${ }^{5-7}$ where it varies from 1 in 100 to 1 in 1700 . The national incidence of PIH is $15.2 \%$ in India, while it is four times higher in primipara women than in multipara. ${ }^{8,9}$

PIH cannot be attributed to single cause as it is multifactorial as disease process.

The disease process affects almost every organ system of body including cardiovascular, renal, endocrine and central nervous system. The changes in the retinal vasculature generally, but not always, correlate with the severity of systemic hypertension. Vasospastic manifestations are reversible and the retinal vessels rapidly return to normal after delivery. ${ }^{2}$ There is paucity of data available in the published literature on the prevalence of retinal changes in $\mathrm{PIH}$ from India. Therefore, this study was under taken to determine the prevalence of retinal changes in PIH and association between the retinal changes and severity of PIH.

Objective of the study is to determine the prevalence of retinal changes in pregnancy induced hypertension and to study the association between retinal changes and severity of the PIH.

\section{METHODS}

\section{Study design and setting}

A hospital based cross-sectional study was conducted in the setting of department of Obstetrics and Gynaecology, JSS Medical College, Mysore, Karnataka, during the year 2004-2006.

\section{Inclusion and exclusion criteria}

All antenatal pregnant women who fulfilled the diagnostic criteria of PIH (>24 weeks of pregnancy, high arterial blood pressure and proteinuria) admitted in Obstetric ward, were included in this study. Patients who had pre-existing diabetes or hypertension or renal disease or hazy media which did not permit fundus visualization were excluded from the study.

\section{Sample size and sampling technique}

Since it is a time bound study, during the two year study period a total of 423 antenatal pregnant women who fulfilled the diagnostic criteria were included in the study. A convenient sampling technique was adopted to sample the study subjects.

\section{Method of data collection}

After taking written consent the data was collected by interview method related to:

1. Socio-demographic data.
2. Obstetric profile of the study subjects.

3. Clinical profile of the study subjects.

4. Clinical examination which included fundoscopic examination.

After taking history for any eye symptoms, anterior segment was examined with torch light on the bed itself. Both pupils were dilated with $1 \%$ tropicamide eye drops and fundus examination was done by ophthalmologist with direct ophthalmoscope in a semi dark room in the ward. Hypertensive retinopathy changes seen in right or left or both eyes, was taken as positive findings in that patient. The retinal changes (hypertensive retinopathy) were graded according to Keith Wagener classification into: grade I - mild generalized arterial attenuation, particularly of small branches; grade II - more severe grade I + focal arteriolar attenuation; grade III - grade II + haemorrhages, hard exudates, cotton wool spots; Grade IV - grade III = optic disc swelling (papilloedema).${ }^{10}$ The $\mathrm{PIH}$ was graded as preeclamsia (mild and severe), Imminent eclampsia and eclampsia based on the standard diagnostic criteria. ${ }^{11}$ All the findings were noted on a data sheet.

\section{Statistical Analysis}

All the collected data was entered into an excel sheet and after appropriate data cleaning, the data was transferred and analysed using SPSS software version 22. Appropriate descriptive statistics like percentages and mean, standard deviation are used to describe the sociodemographic, risk factor variables. The difference in the prevalence of retinal changes among various groups of $\mathrm{PIH}$ was tested using Chi-square test and $\mathrm{p}$ value of less than 0.05 was considered to be significant.

\section{RESULTS}

A total of 423 patients of PIH were examined. Majority $(79.6 \%)$ were in the age group of $20-25$ years. The mean age of patients was 22.7 years with a standard deviation of 3.31 years. Nearly two thirds of them were BPL card holders $(60.8 \%)$ and remaining were APL card holders $(39.2 \%)$. Two thirds of women were primigravida and one third of them were multigravida. The gestation period ranged from 25 weeks to 40 weeks with mean gestation of $35.9 \pm 4.13$ weeks (Table 1 ).

Out of 423 patients, 81 (19.1\%) had mild PIH, 99 $(23.4 \%)$ had severe PIH and $153(36.2 \%)$ had imminent eclampsia with associated symptoms of blurring of vision, severe headache and in the remaining $90(21.3 \%)$ had eclampsia (Table 2).

Out of the 423 patients with PIH, the prevalence of retinal changes (hypertensive retinopathy changes) was noted in $181(42.7 \%)$ patients (Table 3$)$. The prevalence of retinopathy changes was more among patients with imminent eclampsia (76.5\%) and eclampsia patients $(50 \%)$. As the severity of the PIH increased the Odds of 
women developing retinopathy also increased substantially from OR: 17.6; 95\% CI: 3.1 - 136.3 in severe PIH to OR: 253; 95\% CI: 47.2 - 1935 in Imminent eclampsia and this association between the severity of $\mathrm{PIH}$ and the development of retinopathy changes was found to be statistically significant (Table 4).

Table 1: Socio-demographic and obstetric profile of the patients $(\mathrm{N}=423)$.

\begin{tabular}{|lll|}
\hline Variable & Frequency & Percentage \\
\hline Age group & \multicolumn{2}{|c|}{} \\
\hline 20 - 25 yrs & 337 & 79.6 \\
\hline $26-30$ yrs & 78 & 18.4 \\
\hline$>30$ yrs & 8 & 1.9 \\
\hline Mean \pm SD & $22.77 \pm 3.31$ \\
\hline Socio-economic status & \\
\hline APL & 166 & 39.2 \\
\hline BPL & 257 & 60.8 \\
\hline Gravida & & \\
\hline Primigravida & 282 & 66.7 \\
\hline Multigravida & 141 & 33.3 \\
\hline Gestation period & & \\
\hline $24-28$ wks & 18 & 4.3 \\
\hline 28 - 32 wks & 45 & 10.6 \\
\hline
\end{tabular}

\begin{tabular}{|lll|}
\hline $33-36$ wks & 107 & 25.3 \\
\hline$>37$ wks & 253 & 59.8 \\
\hline Mean \pm SD & $35.9 \pm 4.13$ & \\
\hline
\end{tabular}

Table 2: Distribution of study subjects based PIH type.

\begin{tabular}{|lll|}
\hline PIH type & Frequency & Percentage \\
\hline Mild PIH & 81 & 19.1 \\
\hline Severe PIH & 99 & 23.4 \\
\hline Imminent eclampsia & 153 & 36.2 \\
\hline Eclampsia & 90 & 21.3 \\
\hline Total & 423 & 100.0 \\
\hline
\end{tabular}

Table 3:Prevalence of retinal changes based on PIH type.

\begin{tabular}{|lll|}
\hline Retinal changes & Frequency & Percentage \\
\hline Grade I & 136 & 32.1 \\
\hline Grade II & 18 & 4.3 \\
\hline Grade III & 9 & 2.1 \\
\hline Grade IV & 18 & 4.3 \\
\hline Normal & 242 & 57.2 \\
\hline Total & 423 & 100.0 \\
\hline
\end{tabular}

Table 4: Prevalence of retinal changes based on PIH type.

\begin{tabular}{|llllll|}
\hline PIH type & Total no. of pts & Pts with retinal changes & Prev rate $(95 \% \mathrm{CI})$ & OR $(95 \%$ CI $)$ & P value \\
\hline Mild PIH & 81 & 1 & $1.2(0.2-6.6)$ & 1 & - \\
\hline Sev PIH* & 99 & 18 & $18.2(11.8-26.9)$ & $17.6(3.1-136.3)$ & $<0.001$ \\
\hline IE** & 153 & 117 & $76.5(69.2-82.5)$ & $253(47.2-1935)$ & $<0.001$ \\
\hline Eclampsia & 90 & 45 & $50.0(39.8-60.1)$ & $78.3(14.4-600)$ & $<0.001$ \\
\hline Total & 423 & 181 & $42.8(38.2-47.5)$ & - & - \\
\hline
\end{tabular}

*Severe PIH; **Imminent eclampsia.

Table 5: Association of PIH type, obstetric profile with retinal changes.

\begin{tabular}{|c|c|c|c|c|c|}
\hline \multirow[t]{2}{*}{ Parameter } & \multicolumn{5}{|c|}{ Retinal changes } \\
\hline & Grade I & Grade II & Grade III\&IV & Normal & $P$ value \\
\hline \multicolumn{6}{|l|}{ PIH type } \\
\hline Mild PIH (n=81) & $1(1.2)$ & $0(0.0)$ & $0(0.0)$ & $80(98.8)$ & 0.000 \\
\hline Sev PIH (n=99) & $18(18.2)$ & $0(0.0)$ & $0(0.0)$ & $81(81.8)$ & \\
\hline$* \operatorname{Im} \operatorname{Ecl}(\mathrm{n}=153)$ & $81(52.9)$ & $9(5.9)$ & $27(17.6)$ & $36(23.5)$ & \\
\hline Eclampsia $(n=90)$ & $36(40.0)$ & $9(10.0)$ & $0(0.0)$ & $45(50.0)$ & \\
\hline \multicolumn{6}{|l|}{ Agegrp } \\
\hline $20-25$ yrs $(n=337)$ & $118(34.7)$ & $18(5.4)$ & $27(8.0)$ & $175(51.9)$ & 0.000 \\
\hline $26-30$ yrs $(n=78)$ & $18(23.1)$ & $0(0.0)$ & $0(0.0)$ & $63(76.9)$ & \\
\hline$>30$ yrs $(\mathrm{n}=8)$ & $0(0.0)$ & $0(0.0)$ & $0(0.0)$ & $8(100.0)$ & \\
\hline \multicolumn{6}{|l|}{ Gravida } \\
\hline Multi $(n=141)$ & $63(44.6)$ & $8(5.7)$ & $0(0.0)$ & $70(49.6)$ & 0.000 \\
\hline $\operatorname{Primi}(\mathrm{n}=282)$ & $73(25.5)$ & $9(3.2)$ & $27(9.6)$ & $174(61.7)$ & \\
\hline \multicolumn{6}{|l|}{ Gestation } \\
\hline $24-28$ wks $(n=18)$ & $0(0.0)$ & $9(50.0)$ & $9(50.0)$ & $0(0.0)$ & 0.000 \\
\hline $28-32$ wks $(n=45)$ & $9(20.0)$ & $0(0.0)$ & $9(20.0)$ & $27(60.0)$ & \\
\hline $33-36$ wks $(n=107)$ & $73(67.3)$ & $0(0.0)$ & $9(8.4)$ & $26(24.3)$ & \\
\hline$\geq 37$ wks $(n=253)$ & $54(21.3)$ & $9(3.5)$ & $0(0.0)$ & $190(75.1)$ & \\
\hline
\end{tabular}


Out of the 423 patients with $\mathrm{PIH}$, the prevalence of retinal changes (hypertensive retinopathy changes) was noted in $181(42.7 \%)$ patients (Table 3$)$. The prevalence of retinopathy changes was more among patients with imminent eclampsia $(76.5 \%)$ and eclampsia patients (50\%). As the severity of the PIH increased the Odds of women developing retinopathy also increased substantially from OR: 17.6; 95\% CI: 3.1 - 136.3 in severe PIH to OR: 253; 95\% CI: 47.2 - 1935 in Imminent eclampsia and this association between the severity of $\mathrm{PIH}$ and the development of retinopathy changes was found to be statistically significant (Table 4).

Grade I retinal changes were the commonest among all the groups of PIH. Only grade I retinal changes were noted in mild and severe PIH. However in Imminent eclamptic patients all grades of retinal changes were noted (grade I: $52.9 \%$, grade II: $5.9 \%$, grade III and IV: $17.6 \%$ ) and this difference in the distribution of retinal changes among women with different types of PIH was found to be statistically significant (Table 5).

All grades of retinopathic changes were observed more among women in the younger age group between 20-25 years compared to other age groups and this difference was found to be statistically significant. Similarly in primigavida women all grades of retinopathy changes were noted compared to multigravida women where only grade I and II changes were observed and this difference was found to be statistically significant (Table 5).

\section{DISCUSSION}

Preeclampsia is a multisystem hypertensive disorder which is a clinical syndrome that afflicts $3-5 \%$ of pregnancies and is a leading cause of maternal mortality, especially in developing countries. ${ }^{12,13}$ In pregnancy induced hypertension, the various pathological changes in different organs of the body can be studied directly visualizing the ocular fundus and may give a true index of changes in vascular system of brain and retina. ${ }^{14}$

In the present study over a period of two years 423 cases of PIH patients were studied among hypertensive retinopathy changes were noted in 181 cases $(42.8 \%$; 95\% CI: 38.2 - 47.5) (Table 2). Similar studies conducted elsewhere showed that the prevalence of retinopathy in $\mathrm{PIH}$ patients ranges from $38.46 \%, 45 \%, 58 \%, 59 \%$ to $60 \% .^{15-19}$

In the present study the grade I retinopathy (narrowing of retinal arterioles) was the commonest fundoscopic finding, grade III and IV changes were noted in few patients (Table 3 ). These findings were inconsonance with other studies conducted elsewhere. ${ }^{15,17-19}$

It has been described in the literature that among PIH patients, in $30 \%$ to $100 \%$ of patients visual system may be affected by and the most common abnormality seen in the fundus is narrowing of retinal arterioles. ${ }^{2}$ Among patients with preeclampsia and eclampsia there is a wide spectrum of fundoscopic findings and visual problems reported from different countries ranging from focal/generalized narrowing of retinal arterioles to serious retinal detachment. ${ }^{20}$ However with the current methods of early diagnosis and treatment the incidence of such severe retinopathy changes has come down. In the present study we did not find any case of serous retinal detachment. However, Rasdi et $\mathrm{al}^{21}$ reported a case of serous retinal detachment from Malaysia.

In the present study significant correlation was observed between the severity of PIH and the development of retinopathy changes where in as the severity of the PIH increased the Odds of women developing retinopathy also increased substantially from OR: 17.6; 95\%CI: 3.1 136.3 in severe PIH to OR: 253 ; 95\% CI: 47.2 - 1935 in Imminent eclampsia (Table no. 04). Similar association between the severity of PIH and retinopathy changes were noted in other studies. ${ }^{16,18,22}$

In the present study younger the age of the women (20-25 years) higher is the prevalence of retinal changes (48.3\%) and higher proportion of Grade III and Grade IV changes (8\%) compared to rest of the age groups and this difference was found to be statistically significant (Table no. 05). This observation was in accordance with S C Reddy et $\mathrm{al}^{23}$ and Rajalaxmi Kamath et al. ${ }^{19}$

In our study though the prevalence of retinal changes was more among multigravida women (50.3\%) with predominantly grade I changes, primigravida women apart from grade I and II $(28.7 \%)$, grade III and IV $(9.6 \%)$ retinal changes were more common compared to multigravida women. Early the onset of PIH (24-28 weeks of gestation) more are the changes of development of grade III and grade IV (50\%) retinal changes compared to other groups and was found to be statistically significant. The earlier the development of preeclampsia greater the chances of retinopathy. Similar association was observed by Rajalaxmi Kamath et $\mathrm{al}^{19}$ and other studies. $^{22,24-26}$

As described in the literature, the wellbeing of the foetus depends on the placental circulation and it is believed that the vascular changes in the placenta can be indicated by the presence of changes in the retinal arterioles and retinal haemorrhages and therefore ophthalmoscopic examination of mother's fundus may give a clue to similar micro-circulation changes in the placenta and indirectly to the foetal wellbeing. Fundus examination in patients with $\mathrm{PIH}$ is an important clinical evaluation to predict adverse foetal outcomes. $^{27}$

\section{CONCLUSIONS}

Regular fundus examination in all cases of PIH with special emphasis in younger, primigravida women and early onset of PIH patients results in a proper assessment of the clinical status of the patient. Therefore, by repeated 
fundus examinations at regular intervals one can assess the severity of the disease and also response to treatment instituted thereby improving the feto-maternal outcome by managing the pregnancy judiciously.

\section{ACKNOWLEDGMENT}

We the sincerely thank the study subjects and the family members of the patients for their co-operation and support for the smooth conduct of the study. The authors thank Dr. Roopa Prakash, Associate Professor and Dr. Ambarisha Bhandiwad, Professor and Head, and all staff of Department of OBG, Professor and Head, Department of Ophthalmology, JSS Medical College, Mysore for their guidance and support. The authors are also grateful to authors/editors/publishers of all those articles, journals and books from where the literature for this article has been reviewed and discussed.

Funding: No funding sources Conflict of interest: None declared

Ethical approval: The study was approved by the Institutional Ethics Committee

\section{REFERENCES}

1. Subramaniam V. Seasonal variation in the incidence of preeclampsia and eclampsia in tropical climatic conditions. BMC Womens Health. 2007;7:18.

2. Richard RO. Pregnancy induced hypertension (preeclampsia-ecclampsia) In: Schachat AP, Murphy RB, eds. Retina. $2^{\text {nd }}$ ed. St Louis: Mosby, 1994: 140512.

3. Sibai BM, Cunningham FG. Prevention of preeclampsia and eclampsia. In: Lindheimer MD, Roberts JM, Cunningham FG editors; Chesley's Hypertensive Disorders of Pregnancy. $3^{\text {rd }}$ ed, Elsevier, New York, 2009:215.

4. Douglas KA, Redman CWG. Eclampsia in the United Kingdom. Br Med J. 1994;309:1395-1400.

5. World Health Organization; International collaborative study of hypertensive disorders of pregnancy. Geographic variation in the incidence of hypertension in pregnancy. Am J Obstet Gynecol. 1988;158(1):80-3.

6. Crowther CA. Eclampsia at Harare maternity hospital. An epidemiological study. S Afr Med. 1985;68(13):927-9.

7. Bergstrom S, Povey G, Songane F, Ching C. Seasonal incidence of eclampsia and its relationship to metereological data in Mozambique. J Perinat Med. 1992;20(2):153-158.

8. Dutta DC. Text book of obstetrics. 3rd ed. New Central Book Agency (Pvt) Ltd. Calcutta. 1995:230-6.

9. ACOG Diagnosis and Management of Preeclampsia and Eclampsia. ACOG Practice Bulletin. 2002;33.
10. Kanski JJ. $2^{\text {nd }}$ ed. Oxford: Butterworth Heinmann. Clinical ophthalmology-a systematic approach. 1989;329.

11. Classification of hypertension in pregnancy (National blood pressure education program 2000 and ACOG 2013.

12. Noraihan MN, Sharda P, Jammal AB. Report of 50 cases of eclampsia. J Obstet Gynaecol Res. 2005;31(4):302-9.

13. Nalliah S, Thavarasha AS. Transient blindness in pregnancy induced hypertension. Int J Gynaecol Obstet.1989;29(3):249-51.

14. Abu Samra K. The eye and visual system in the preeclampsia/eclampsia syndrome: what to expect? Saudi J of Opthal. 2013;27(1):51-3.

15. Das KA, Jaisal P. Fundus Changes in Pregnancy Induced Hypertension. Int $\mathrm{J}$ Med Res Prof. 2016;2(2):47-50.

16. Tadin I, Bojić L, Mimica M, Karelović D, Dogas Z. Hypertensive retinopathy and preeclampsia. Coll Antropol. 2001;25(Suppl 0):77-81.

17. Reddy SC, Nalliah S, Rani SA, George PK, Who TS. Fundus changes in pregnancy induced hypertension. Int J Ophthalmol. 2012;5(6):694-7.

18. Reddy SC. Ocular fundus changes in toxemia of pregnancy. The Antiseptic.1989;86(7):367-72.

19. Kamath RK, Nayak SR. Preeclampsia/Eclampsia and retinal micro vascular characteristics affecting maternal and foetal outcome: a prospective study amongst south indian pregnant women. IJIRD. 2013;2(11): 444-8.

20. Dornan KJ, Mallek DR, Wittmann BK. The sequelae of serous retinal detachment in preeclampsia. Obstet Gynaecol. 1982;60(5):657-63.

21. Rasdi AR, Nik-Ahmad-Zuki NL, Bakiah S, Shatriah I. Hypertensive retinopathy and visual outcome in hypertensive disorders in pregnancy. Med J Malaysia. 2011;66(1):42-7.

22. Jaffe G, Schatz H. ocular manifestations of preeclampsia. Am J Ophthalmol. 1987;103(3 Pt1):30915.

23. Reddy SC. Raghavamma TV. Retinal detachment in preeclampsia- a case report. J Obstet Gynaec of India. 1981;31(3):501-3.

24. McEvoy M, Runicman J, Edmonds DK, Kerin JF. Bilateral retinal detachment in association with preeclampsia. AustNZ J Obstet Gynaecol. 1981;21(4):246-7.

25. Jyotsana, Sharma AK, Bhatt S. Reversible blindness in severe preeclampsia and Eclampsia. JK Sci. 2004;6:435.

26. Ryan SJ, Sunness JP. Pregnancy and retinal disease. In: Ryan SJ, eds. Retina. 1994;2:1393-403.

27. Karki P, Malla KP, Das H, Uprety DK. Association between pregnancy induced hypertensive fundus changes and fetal outcome. Nepal J Ophthalmol. 2010;2(1):26-30.

Cite this article as: Varija T, Vanaja D, Sindhura, Raghavenda B. A study of prevalence and association of fundus changes in pregnancy induced hypertension. Int J Reprod Contracept Obstet Gynecol 2016;5:1375-9. 